\title{
Comunicação como epistemologia do sul: do reconhecimento à emergência do acontecimento*
}

\section{Communication as southern epistemology: from recognition to the emergence of the event}

\author{
JOSÉ LUIZ A IDAR PRA DO** \\ Pontifícia Universidade Católica de São Paulo, Programa de Pós-Graduação em Comunicação e \\ Semiótica. São Paulo - SP, Brasil
}

\section{RESUMO}

Busca-se tematizar a comunicação como um campo tensivo estabelecido a partir de lutas pelo reconhecimento, podendo conduzir ao acontecimento. Partiremos da necessidade da teoria da comunicação em se mostrar materialista e continuaremos pelo que levou Honneth a criticar Habermas, indicando que a teoria da ação comunicativa não considera o conflito, resultando num déficit sociológico. Em seguida pensaremos em uma epistemologia do sul na qual a crítica possa ser erigida a partir de situação de desrespeito ou de necessária construção de identidade do colonizado, a despeito dos regimes de visibilidade disponíveis. $\mathrm{O}$ acontecimento implica a mudança do circuito de visibilidade a partir do qual os sujeitos da comunicação se constituem.

Palavras-chave: Luta pelo reconhecimento, teoria do acontecimento, teoria crítica da comunicação, Alain Badiou, Axel Honneth

\section{ABSTRACT}

We seek to foreground the communication as a tensive field established from the struggle for recognition, which may lead to the event. We will start from the necessity for this communication theory to stand as materialistic and tread the path that led Honneth to criticize Habermas, indicating that the theory of communicative action does not consider the conflict, resulting in a sociological deficit. As a result, we will think about a southern epistemology in which critique can be examined from a situation of disrespect, or the necessary construction of identity of the colonized, despite the visibility regime available. The event involves the change of visibility circuit from which the subjects of communication constitute themselves.

Keywords: Struggle for recognition, event theory, critical theory of communication, Alain Badiou, Axel Honneth

\footnotetext{
* A primeira versão deste texto foi apresentada no DTI Epistemologia, Teoria e Metodologia da Comunicação do XIV Congresso Internacional IBERCOM 2015, na Universidade de São Paulo, São Paulo, de 29 de março a 2 de abril de 2015.

** Professor doutor do Programa de Estudos Pós-Graduados em Comunicação e Semiótica da PUC-SP; organizador e coordenador das hipermídias A invenção do Mesmo e do Outro na mídia semanal e Regimes de visibilidade em revistas; editor da revista Galáxia; autor dos livros Habermas com Lacan (EDUC, 2014) e Convocações biopolíticas dos dispositivos midiáticos (EDUC, 2013). E-mail: aidarprado@ gmail.com.
} 
URATA-SE, NESTE TEXTO, de pensar a comunicação na contramão dos dispositivos midiáticos, caracterizados pelas máquinas de expres-

são que privilegiam a construção de "eus" empreendedores de si mesmos num regime de visibilidade que imaginariza e idealiza a vida condominial. Nela, o síndico-enunciador comunicacional faz circular regras gestoras ao invés de uma política, operando a colonialidade, e isso produz sujeitos por identificação, sujeitos que guiam sua vida dirigindo-se a uma otimização utilitária de ações: eu invisto naquilo que me capitaliza, naquilo que transformará meus filhos em capitalizadores racionais, em proprietários de bens e atributos materiais e imateriais (visando a busca do sucesso nesta lógica empreendedorista). Na contramão desse dispositivo, Safatle tem proposto pensar uma política como um circuito de afetos diferente da capitalização, uma política pensada a partir de outra aesthesis, ancorada em outros afetos e em uma diversa relação sensível com os corpos.

Seguiremos quatro passos principais. a) Em primeiro lugar, tal teoria deve ser pensada como materialista; explicitaremos em que sentido; b) em segundo lugar, essa comunicação não é consensual, pois parte do dissenso, ou seja, é pensada como um campo tensivo a partir do antagonismo de base; isso se mostrará a partir de uma crítica dos pressupostos e postos da teoria da ação comunicativa habermasiana e na contraposição elaborada por Axel Honneth, que propõe uma teoria do reconhecimento; c) pensar tal teoria da comunicação como campo tensivo nos levará a contemplar a emergência de outros circuitos sensíveis (dos afetos) a partir de uma teoria do acontecimento, pensando reconhecimento em sua relação com a emergência do acontecimento disruptivo; d) tal teoria tematizará a questão da visibilidade e da invisibilidade, a fim de redimensionar a "figura atual do homem" (Safatle, 2012), consumidor utilitarista, o que nos conduz a uma epistemologia do sul não guiada pelas teorias pós-modernas do norte.

\section{CONCEPÇÃO MATERIALISTA DA COMUNICAÇÃO}

O que é uma abordagem materialista da comunicação? No livro Absolute recoil, Žižek (2014) diferencia a concepção usual de materialismo de uma concepção mais estrutural, ligada à teoria da linguagem. No marxismo tradicional, materialismo significa que a ideologia (entendida como espelho invertido ideal da realidade) se apoia no processo material extraideológico de reprodução social, e não se considera aqui a dimensão althusseriana da existência material da ideologia nos aparelhos ideológicos do Estado, constituindo uma 
rede institucional de práticas e rituais. A partir de Lacan, é possível considerar outra materialidade,

específica das próprias ideias, imanentes à ordem simbólica "ideal", na medida em que essa ordem não pode ser reduzida à expressão do significado, mas funciona como uma máquina sem significado, máquina que é o Grande Outro antes de qualquer materialização em instituições ou práticas materiais. (Žižek, 2014: loc. $\left.1122^{1}\right)$.

Em outras palavras, aqui a materialidade não significa apenas que as ideias são fundadas no processo material social, mas que elas têm a sua materialidade; as ideias são inscrições que marcam o mundo. A dificuldade de se implantar um estado ideal de coisas (um universo moral, por exemplo) não decorre da lacuna entre a pureza do ideal e a dificuldade impura do mundo empírico, mas está no próprio cerne da linguagem, ou seja, no centro da linguagem está um fosso, um torto, um dano primordial que movimenta as marcas simbólicas. Há, portanto, diz Žižek, "uma distorção imanente à linguagem", que se manifesta num movimento de engendrar uma falsa aparência que "não é da ordem da corrupção empírica de uma normatividade original" (Ibid.: loc. 1149). Diz Žižek:

A razão comunicativa de Habermas é aqui emblemática: a ação comunicativa é possível dada a capacidade humana para a racionalidade, mas esta racionalidade não é mais de tipo tradicional, nem a estrutura do cosmos racional imanente (como na tradição aristotélica) nem o racional a priori do sujeito transcendental kantiano. Sabedor de que hoje tal fundacionalismo filosófico não é mais possível, Habermas concebe a racionalidade como uma capacidade inerente à linguagem, especialmente na forma de argumentação. Ele reinterpreta, assim, o horizonte transcendental como um a priori pragmático de fala intersubjetiva: todo ato de fala tem a meta objetiva de entendimento mútuo e os seres humanos possuem a competência comunicativa para alcançar o entendimento. A fala argumentativa se baseia numa normatividade inerente - a ausência de força de coerção, a busca mútua por entendimento, o poder propulsor do melhor argumento - que faz a comunicação possível. Nessa direção, Habermas se esforça para fundamentar as metas de emancipação humana e para manter uma estrutura ética universalista: a normatividade de que ele fala não é um ideal externo, mas é imanente à nossa participação na intersubjetividade linguística - quando falo com os outros, isso implica que eu obedeço tais normas mesmo se conscientemente eu as viole. Esta pragmática a priori inerente à linguagem
1. Usa-se aqui a edição kindle do livro, daí a referência loc, dada no dispositivo. 
é irredutível: ninguém pode passar ao largo no sentido transcendental estrito. [...] Para Habermas todos os outros usos da linguagem (mentir, enganar, seduzir etc.) são derivativos: distorções empíricas secundárias da normatividade inerente, condicionadas por relações de poder e dominação ou pela busca de interesses privados (Žižek, 2014: loc. 1122).

Entretanto, para uma tradição mais ligada à psicanálise e ao estruturalismo, há todo um campo em que afloram os parasitas, no dizer de Derrida (1991), constituído por atos falhos, mentiras, fraudes, fingimentos, que são a origem da própria linguagem, inscritos em sua própria estruturação, não somente distorções secundárias de sua normatividade imanente. A impureza não é uma imperfeição empírica, mas a priori, transcendental. Žižek aborda essas distorções, esses torts, a partir da dimensão performativa da interação sócio-simbólica, do jogo dos papéis sociais, de obediência a regras civilizadas de polidez em que entra em campo uma causalidade não dos fatos empíricos, mas de ilusões polidas, de maneiras superficiais, de mero fingir - chamados de Lacan "o grande Outro", o nível das mentiras sinceras, da manutenção das aparências. Essa polidez é mais do que a obediência a uma legalidade externa e menos que uma atividade moral pura - é o domínio ambíguo e impreciso daquilo que não somos estritamente obrigados a fazer, mas que se espera que façamos. Trata-se das regulações não ditas, implícitas, ligadas a questões de tato e ao fato de que o falante tem uma relação não reflexiva, que é parte de nossa sensibilidade espontânea, uma textura densa de costumes e expectativas que constituem uma substância herdada ${ }^{2}$.

Tal direção tira do centro da linguagem certa concepção de transparência, de expressabilidade máxima, de entendimento como telos, de subsunção de

2. Esse é para Žižek o domínio da ideologia: "é o ar que respiramos espontaneamente em nossas interações diárias, nas atitudes que aceitamos como dados autoevidentes. Pondo em termos althusserianos, é o domínio dos dispositivos (ou aparelhos) e práticas ideológicos, um domínio que, para usar os próprios termos de Kant, permite aos indivíduos 'esquematizar' suas normas legais e morais abstratas, fazendo-as parte de suas experiências vividas" (Žižek, 2014: loc. 1245). que sabemos qual é o uso normal da linguagem, de que temos condições de pensar um contexto da fala presente a si mesmo. Derrida (1991), por exemplo, fazendo o contrapelo dessa metafísica comunicacional, propôs uma inversão na atitude tradicional da metafísica de colocar a escrita sob o guarda-chuva da comunicação, ou seja, a escrita não seria uma comunicação esticada, a operar quando os comunicantes estiverem um longe do outro, devido à distância ou a uma defasagem temporal. Assim, a marca inscritível, que risca o mundo, seja na comunicação oral ou escrita, não seria mais pensada como modificação ontológica da presença. Se antes escrever era comunicar à distância, para Derrida comunicar é uma das espécies do escrever, um efeito de escrita, de inscrição. Não se comunica apenas a partir da presença de um emissor, mas a marca, uma vez produzida, engendra contextos novos em tempos ulteriores, mesmo na ausência do destinador. É por isso que podemos decifrar um código de uma civilização perdida. 


\section{COMUNICAÇÃO COMO CAMPO TENSIVO}

A comunicação, nessa linhagem, não é o transporte de um querer dizer, um pacotinho que circula por um canal, unindo duas consciências, uma emissora e outra receptora-receptiva. A marca, uma vez posta a circular, engendra novos contextos, produzindo comunicações no plural. Para Derrida (1991), toda marca é um grafema, um riscar de mundo, ou seja, aquilo que ele chama de "restância não presente" (Ibid.: 28). Não há, então, experiência de pura presença, somente as cadeias de marcas diferenciais. Essa crítica foi feita para refletir sobre os pressupostos metafísicos da teoria dos atos de fala de Austin e Searle, cujo centro é o de uma plenitude de sentido (ato de fala normal), mas ela serve para examinarmos a teoria da ação comunicativa de Habermas.

O interesse da ideia de performativo, introduzida por Austin e amparada na teoria habermasiana, está na ampliação da ação de linguagem, antes limitada a um constatar dos estados de coisas do mundo, a uma semântica que diz se a coisa está adequada a seu nome. Eu digo que o guarda matou o ativista e tenho de provar isso no tribunal para obter a condenação: a verdade como correspondência e constatação é o centro da atividade da linguagem nesse modelo. Com Austin (1962), a linguagem passa a assumir outra atividade, a de fazer coisas no mundo: ao prometer algo eu enuncio uma frase que, após dita, já é a promessa feita. Falar é fazer. Por que isso interessa à teoria habermasiana? Porque em Habermas faz-se uma crítica de um modo generalizado de uso da linguagem que é instrumental, baseado no modo constatativo, generalizado no mundo sistêmico (da guerra, da economia, dos partidos), em que a verdade é correspondência entre uma descrição de um estado de coisas e esse próprio estado, decorrendo daí o que o filósofo chama de colonização do mundo da vida pelo sistema: a cultura se transforma em mercadoria, tudo vira meta a atingir segundo alternativas e estratégias comparáveis. A diferença de atitude num caso e noutro é a seguinte: enquanto no modo sistêmico o actante constrói metas e escolhe alternativas comparáveis para atingi-las, o que conta no modo comunicativo do mundo da vida, da cultura, é a busca do entendimento para resolução de situações fenomênicas em que estão envolvidos os agentes. Não basta constatar e calcular, é preciso ampliar a linguagem para considerar sua força simbólica, que é diminuída, reduzida, empobrecida no modo sistêmico.

No modo comunicativo habermasiano, a linguagem é o meio supremo de comunicação, em sua função pragmática e não somente semântica. $\mathrm{O}$ modo pragmático é aquele em que a ação dos actantes vale em situação. Corresponde ao regime de interação do ajustamento em Landowski (2014: 47). Se eu verifi- 
co na janela que chove lá fora e posso dizer que o enunciado chove fora agora é verdadeiro, o critério é semântico e a linguagem é constatativa. Por outro lado, se duas pessoas querem se separar e estão tentando chegar a um entendimento para dividir bens e a guarda dos filhos, não se trata de uma linguagem constatativa, mas comunicativa. Pragmática refere-se a esse uso da linguagem em situações concretas do dia a dia, na busca de um entendimento, pela via da comunicação contingente, levando em conta os dados concretos daquela situação, em ato. Como diz Landowski:

Nos processos de ajustamento, a maneira como um ator influencia um outro passa por caminhos bem diferentes: não mais pela comunicação de objetos autônomos (mensagens, simulacros, valores modais ou objetos-valor) que desempenham a função de discursos persuasivos ou dissuasivos no quadro de uma lógica da "junção", mas pelo contato ("contagioso") - o que implica uma problemática da união. [...] Estamos lidando agora com uma interação entre iguais, na qual as partes coordenam suas dinâmicas por meio de um fazer conjunto. E o que lhes permite ajustar-se assim uma à outra é uma capacidade nova, ou ao menos uma competência particular que o modelo precedente [o regime da programação] não tinha chegado a conhecer: a capacidade de se sentir reciprocamente. Para a diferenciar da competência dita modal, nós a batizamos de competência estésica (Ibid.: 50).

Em Landowski temos esse funcionamento pragmático, embora levado adiante de Habermas, na medida em que o autor opera com os aspectos sensíveis da relação comunicativa, que ele chama de estésicos. O que nos interessa aqui é marcar a diferença entre regimes como o da programação e o da manipulação e o do ajustamento, que é o que mais se aproxima da razão comunicativa habermasiana, embora saliente a questão do sensível, além da do inteligível da comunicação.

O problema da teoria habermasiana é duplo: por um lado ela cria um fosso entre a racionalidade instrumental (sistêmica) e a comunicativa e, por outro, pensa a ação comunicativa a partir de um telos da linguagem, como um centro de normalidade a partir do qual eu posso pensar nos desvios e patologias. No centro da linguagem habermasiana há um Outro pleno, emissor de compreensão e expressibilidade (Prado, 2014; Habermas, 2012).

Contra essa visão plena, Derrida (1991) recorre, como vimos, à teoria da linguagem que subjaz à psicanálise, que coloca no centro da linguagem um fosso, um parasita, um vácuo ao redor da qual gravitam as marcas. Como poderíamos dizer com Freud, no centro da linguagem está o ato falho, um 
tort (Rancière, 1996), espécie de emissão do grande parasita do inconsciente. Ao invés de expurgar, de excomungar para longe as aparições espectrais do inconsciente, deixando no centro idealizado da linguagem uma plenitude, o Um, é preciso partir delas para pensar na linguagem impura e desviante como emissões em casos múltiplos, normais e plurais. Ao invés de idealizar uma comunicação plena a partir do princípio da expressabilidade searliana - tudo que pode ser pensado pode ser expresso (Searle, 1970) -, é preciso partir da ideia da diferença sexual lacaniana (Žižek, 2013: 427).

Em sua introdução ao livro Luta pelo reconhecimento, de Axel Honneth, Marcos Nobre indica que Honneth (2003) tenta promover uma reflexão sobre a proposta de Habermas construída a partir de dentro da teoria crítica, afirmando que faltou na teoria da ação comunicativa a consideração da centralidade do conflito. Conforme afirma Honneth (2011), ao postular a ação comunicativa como paradigma crítico, Habermas deu um passo na direção de uma reformulação da crítica social e da saída do negativismo adorniano, centrado na ideia de colonização da cultura (mundo da vida) pelos sistemas, em que vige uma racionalidade com respeito a fins, de tipo estratégico, como a que domina na economia.

A questão que o autor coloca Honneth é: "que fenômenos assumem na teoria da ação comunicativa o papel de testemunhar cotidianamente, antes de qualquer reflexão científica, a conformidade da crítica?" (Honneth, 2011: 134). O problema é que tanto em Adorno quanto em Habermas o foco está "no diagnóstico contemporâneo de que a autonomização dos poderes sistêmicos, atualmente, pode provocar uma dissolução do núcleo social da sociedade" (Honneth, 2011: 133). Entretanto, Habermas considera o potencial positivo das experiências dos agentes comunicativos em seu cotidiano na medida em que tentam resolver situações problemáticas com outros agentes, "dentro de um horizonte de expectativas normativas, cuja decepção sempre pode converter-se novamente em fonte de exigências morais que apontem mais além de formas estabelecidas de poder" (loc. cit.). O que busca Honneth? A teoria crítica deve, para ele, ser capaz de nomear

as experiências e atitudes empíricas que já pré-cientificamente representam um indicador de que seus pontos de vista normativos não estão sem respaldo na realidade. [...] Que fenômenos em geral assumem na teoria de Habermas o papel de testemunhar cotidianamente, antes de toda reflexão científica, a conformidade da crítica? Minha suspeita é a de que neste ponto se abre um abismo na teoria da ação comunicativa que não é de procedência casual, mas de índole sistemática (Honneth, 2011: 134). 
O processo de emancipação sobre o qual Habermas constrói sua teoria crítica não se reflete nas experiências morais dos sujeitos implicados (Ibid.: 135), pois estes percebem suas perdas enquanto lesões em suas pretensões de identidade e não como restrições de regras linguísticas. Para Honneth, a motivação pelo comportamento de protesto social nas camadas sociais mais pobres "não se baseia na orientação por princípios de moral formulados positivamente, mas na experiência de violação de ideias de justiça dadas intuitivamente" (Ibid.: 137). Buscam reconhecimento social, lutam contra o desprezo social dentro de um campo tensivo.

É nessa direção que vai Honneth, a fim de resolver os déficits sociológicos da teoria da comunicação habermasiana, baseada numa pragmática universal. O ponto de partida dessa virada honnetiana é a consideração de que "as condições normativas da interação social não podem ser compreendidas em toda sua amplitude se só se basearem em condições linguísticas de um entendimento livre de coerção" (loc. cit.). Com isso, Honneth amplia o paradigma da comunicação para mais além de uma teoria linguística. A ausência do reconhecimento é o desprezo, que é sempre acompanhado de uma experiência de perda de personalidade, quando o agente comunicativo vive uma tal experiência de desprezo, isto é, acompanhado de vergonha, raiva ou indignação. Para Honneth (2011: 138), existe uma

relação estreita entre as violações causadas aos supostos normativos da interação social e as experiências morais que os sujeitos fazem em sua comunicação diária: se se deterioram aquelas condições, negando a uma pessoa o merecido reconhecimento, então o afetado reage a isso, em geral com sentimentos morais que acompanham a experiência de desprezo, ou seja, com vergonha, raiva ou indignação. Assim, um paradigma da comunicação não compreendido em termos de teoria linguística mas em termos de teoria do reconhecimento pode finalmente preencher o vazio teórico que Habermas deixou aberto em seu desenvolvimento do programa de Horkheimer: pois aqueles sentimentos de injustiça que vêm acompanhados de formas estruturais de desprezo representam um fato social pré-científico, mediante o qual uma crítica das relações de reconhecimento pode mostrar socialmente sua própria perspectiva teórica.

Assim, o deslocamento que empreende Honneth da tensão entre sistema e mundo da vida, recai sobre as experiências de sofrimento sentidas como desprezo, ou seja, "as causas sociais que são responsáveis pela violação sistemática das condições de reconhecimento" (Honneth, 2011: 138). 


\section{QUAL SUJEITO? TRAJETO DO RECONHECIMENTO AO ACONTECI- MENTO}

Safatle retoma a teoria do reconhecimento em seu livro Grande hotel abismo, em que investiga uma figura do sujeito que não dependa da redução egológica da atual figura do homem característica do Eu S/A, ou seja, do ator que busca, no cerne da sociedade globalizada de consumo, o capital do Eu. Se usualmente o sofrimento psíquico se dá quando alguém fracassa no processo de individualização, com a consequente impotência para orientação no mundo social (Safatle, 2012: 6), Safatle enfatiza que ocorre também sofrimento em razão de "estarmos muito presos à entificação da estrutura identitária do indivíduo" (loc. cit.), ou seja, sofremos por sermos esse Eu, por buscar ser este Eu. Isso surge em termos de incapacidade de viver

experiências de não identidade e indeterminação (o que leva, pura e simplesmente, à incapacidade de vivenciar experiências como acontecimentos), ou ainda do isolamento de quem não encontra mais traços de outros em sua própria experiência temporal (perda de historicidade) e do vínculo compulsivo à figura atual do homem (loc. cit.).

Esta busca de Safatle nos leva a pensar em uma comunicação considerada de modo bastante diverso do habermasiano, que pensa o Lebenswelt, a cultura, como um background garantidor de horizontes. Trata-se de repensar safatlianamente o que se entende por ação racional a partir de Adorno e Lacan. Safatle propõe pensar o sujeito não mais como entidade substancial que fundamenta processos de autodeterminação (espécie de sujeito pleno esférico, em busca do sucesso nas ações celebrativas), para "transformar-se no locus da não identidade e da clivagem" (Safatle, 2012: 12). Essa não identidade é apresentada como "negatividade não recuperável para a estruturação de uma subjetividade que não se perde no meio universal da linguagem" (Ibid.: 13).

Existe um sofrimento de determinação a partir de modalizações sociais de um regime de visibilidade que convoca os actantes a se construírem como sujeitos de uma construção do capital do eu (Freire Filho, 2010; Prado, 2013a), que Safatle chama de "figura atual do homem". Para ele, "o vínculo compulsivo a tal figura atual é exatamente aquilo denominado 'redução egológica do sujeito', impossibilidade de pensar aquilo que, no interior da experiência, não se submete à forma do Eu" (Safatle, 2012: 315).

Em Dunker (2015), esse projeto de Eu S/A aparece construído nos condomínios, como o Alphaville em São Paulo: "uma região isolada do resto [...], um bairro artificial, formado por uma série de condomínios interligados, com 
um centro empresarial e comercial, em uma área antes ocupada por posseiros” (Ibid.: 48). O grande apelo para as classes médias altas é a segurança, o acesso aos serviços, a "promessa de uma comunidade racialmente integrada" (Ibid.: 49). Ora, a psicanálise

nos ensina a reconhecer com suspeita tais produções sociais, que acenam com uma região de extraterritorialidade protegida, um espaço abrigado onde se concentraria a realização do prazer retinto de liberdade (Ibid.: 53).

O que vemos então no condomínio, em funcionamento? Diz Dunker:

Um lugar fortemente delimitado (muros), no qual a representação é substituída pela administração funcional (síndico), que cria uma rígida lei própria (regulamentos) conferindo suplemento de identidade moral a seus habitantes. Nele ganham substância ideais de autorrealização e sucesso. Ao fim e ao cabo, um condomínio é em geral adquirido por meio de uma dívida extensa, que fixa o sujeito a um compromisso futuro e introduz um grande distanciamento físico de sua família ou de seu bairro de origem (Ibid.: 58).

Instalada a lógica condominial entre nós, o que acontece com o mal-estar e o sofrimento? Ora o condomínio é uma forma do laço social, em que parte da população está dentro dos muros e parte fora, o que produz conjuntos historicamente constituídos de mal-estar, sofrimento e sintoma. Vejamos isso mais de perto:

É preciso lembrar que o conceito de condomínio toca de modo breve o universo invertido e periférico das favelas. A fusão sintética dos dois universos opostos é naturalmente a prisão. A lógica concentracionária reproduz o estado de exceção, alternando a face liberal da formação de muros, que trabalha pela instrumentalização dos dispositivos de regulação, e a face disciplinar dos muros, que opera reativamente pelo controle dos excessos. Entre uma e outra, há a face romântica do condomínio, pela qual a estrutura se mostra de modo mais visível como idealização. Ou seja, três formas complementares de determinação, como bom uso da liberdade, como aperfeiçoamento da ordem e como idealização da experiência, concorrem na sustentação da fantasia narcísica dos muros (Dunker, 2015: 68).

Através desse laço social do condomínio não se trata mais de fazer progredir os atrasados, os pobres, como diz Dunker, mas de "localizar e conter o resíduo como pobreza estrutural globalizada” (loc. cit.). Os problemas sociais 
devem ficar fora dos muros e cria-se barreiras entre globalizados afluentes e localizados empobrecidos.

Conforme Dunker, "todo sofrimento é uma reflexão que ainda não encontrou seu ponto de virada, o desejo de que as coisas sejam diferentes". Com isso, há uma perda de experiência e um bloqueio: "que se expressa ainda como impotência de formar, transmitir ou generalizar experiências" (loc. cit.). O sofrimento pode ser excessivamente nomeado (codificado em formas jurídicas, morais ou clínicas) ou insuficientemente nomeado (mal-estar difuso, angústia flutuante). Não sofremos somente por excesso de experiências improdutivas de determinação, causadas pelas instituições disciplinares e por discursos institucionalizados; sofremos também por déficit de experiências produtivas de indeterminação, que são necessárias para que "a liberdade se exprima em ato real e não apenas no reconhecimento indireto, através da submissão e da mediação dos sistemas simbólicos reunidos por uma utópica ou administrada unidade teológico-política" (loc. cit.). Já vimos isso acima com Safatle, quando ele evoca a importância das experiências de não identidade. Importante é a ideia, para Dunker, de que nem toda indeterminação é a negação de uma determinação anterior.

Existem experiências de indeterminação que são produtivas. O sujeito não sofre, portanto, apenas em função de um excesso sistêmico de determinação, por viver sob as regras do síndico condominial, mas também por uma falta de experiências produtivas de indeterminação. É isso o que não tem sido considerado nas teorias sobre brasilidade. Conforme Safatle: "Tal experiência produtiva só pode ser corretamente pensada quando somos capazes de abandonar a ilusão de que a linguagem pré-filosófica do senso comum já não traz no seu bojo uma figura antropológica do homem à qual deveríamos nos conformar" (Safatle, 2012: 314). Sob essa perspectiva, a teoria da comunicação não deveria pensar a comunicação como um ideal de plenitude de expressabilidade, mas como espaço tensivo que gira ao redor do fosso-torto, do parasita de que fala Derrida, em que um acontecimento pode engendrar a política, a mudança, ou seja, a transformação de mundo a partir de uma descontinuidade efetiva, de uma singularidade definida como "ente cujo pensamento não pode reduzir-se a seu contexto mundano" (Badiou, 2008: 395). É nesse rumo que deveríamos repensar a teoria da comunicação. Penso que há autores brasileiros que tentam esse direcionamento, principalmente aqueles que trabalham com a teoria do acontecimento, em suas várias vertentes (pragmática, com Vera França, deleuziana, com Ciro Marcondes, entre outros).

Devemos colocar essa experiência advinda do sofrimento de determinação ao lado das experiências de agentes que buscam reconhecimento, dentro 


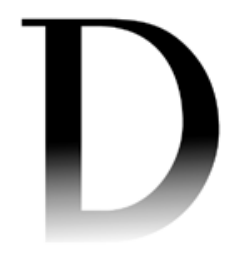

\section{Comunicação como epistemologia do sul: do reconhecimento à emergência do acontecimento}

do antagonismo social, em que a voz que não tem espaço na partilha social demanda advento no campo social. Levar isso em conta implica considerar a negatividade e o valor de suas experiências (o que diferencia nossos autores daqueles deleuzianos). Há, por assim dizer, uma potência da infinitude nesse sofrimento de indeterminação, que as convocações biopolíticas e midiáticas buscam esconjurar, medicalizando todo sintoma que aponta para uma paixão desabilitadora do actante-do-capital-do-eu. De acordo com a psicanálise,

podemos sofrer não apenas por sermos incapazes de nos constituirmos como indivíduos, isto no sentido de não alcançarmos a realização bem sucedida de processos de socialização e individuação. Podemos sofrer por sermos apenas um indivíduo (Safatle, 2012: 316).

Safatle procura, no rastro de certo Adorno e de Lacan, como vimos, construir uma teoria do sujeito que esteja "liberada das amarras do pensamento da identidade e de uma antropologia fundada nas normatividades definidoras da humanidade do homem" (loc. cit.). A teoria da comunicação que considera sua postura crítica a partir de uma teoria do reconhecimento cuja experiência desperta a partir do sofrimento (de determinação e de indeterminação) também deve evitar as aporias do humanismo, que conecta com o pensamento da identidade e com a figura biopolítica do sujeito saudável e de sucesso. Assim, a teoria da comunicação que considera essa figura do sujeito para além da figura atual do homem deve se pensar também no âmbito do descolonialidade.

\section{RECONHECIMENTO E VISIBILIDADE}

Esse tipo de teoria social imaginada por Safatle não abandonou o pensamento de uma emancipação social, embora ela não seja mais posta em termos modernos, pois, como diz Santos (2007: 18), "os instrumentos que regularam a discrepância entre reforma e revolução, entre experiências e expectativas, entre regulação e emancipação, essas formas modernas estão hoje em crise". Além disso, as teorias do norte, de raiz eurocêntrica, também não nos atendem de modo satisfatório, apesar do impulso que sofremos para nos internacionalizar, pois as teorias do norte aqui estão fora de lugar. Em nossa realidade social não vigora, como diz Amálio Pinheiro, o conceito progressivo e linear de sucessão, mas a atividade não ortogonal do barroco em suas marchetarias (Pinheiro, 2013). A não consideração dessas diferenças leva ao desperdício de experiência. Afirma Santos (2007: 24): "Experiências muito locais, não muito conhecidas nem legitimadas pelas ciências sociais hegemônicas, são hostiliza- 
das pelos meios de comunicação social, e por isso têm permanecido invisíveis, 'desacreditadas"'.

Os regimes de visibilidade criam formas de ver e de ser visto em que certo contingente de pessoas se sente invisível, não percebido, vivendo para lá dos muros dos condomínios. Segundo Souza (2006: 10), a generalização liberal

imagina a sociedade composta de um conjunto de homo economicus, intercambiáveis e fungíveis, com as mesmas disposições de comportamento e as mesmas capacidades de disciplina, autocontrole e auto-responsabilidade, as quais seriam encontradas em todas as classes.

Nesse enquadramento ideológico, o marginalizado "é percebido como se fosse alguém com as mesmas capacidades disposicionais do indivíduo de classe média" (loc. cit.), só que ele, por um acaso ou por falta de competência, não se ergueu na escala social, não se fez visível com um eu forte, cheio de competência comunicativa, "sendo a sua situação de privação facilmente reversível, bastando para isso uma ajuda passageira e tópica do Estado para que ele possa andar com as próprias pernas" (loc. cit.. Para Souza,

As diversas concepções que imaginam que a integração subordinada seja reversível por um ato de vontade e um 'passe de mágica' não são muito diferentes disso. Do mesmo modo, as diversas formas de 'glorificação do oprimido' que grassam nas ciências sociais de todos os matizes levam água ao moinho da autoindulgência, da passividade e da manutenção do status quo. Elas desconhecem que a reprodução das classes marginalizadas envolvem a produção e a reprodução das pré-condições morais, culturais e políticas da marginalidade. Elas desconhecem que a miséria dos desclassificados é produzida objetivamente não apenas sob a forma de miséria econômica, mas também sob a forma de miséria emocional, existencial e política (Souza, 2006: 10).

Como quebrar esse círculo vicioso? Souza recusa as vias de glorificar o oprimido, ou aceitar acriticamente o politicamente correto. É preciso "reconstruir o vínculo perdido entre padrão de modernização, dominação opaca e impessoal, formação de consensos 'pré-reflexivos' e naturalização da desigualdade" (Souza, 2006: 10). Ele propõe-se a construir uma teoria alternativa da ação social para o contexto da modernidade periférica brasileira. Nossa teoria crítica da comunicação deveria também considerar esse posicionamento, pois não se trata de fazer uma mera descrição "da realidade imediata tal qual na reprodução narrativa dos estados subjetivos 
de humilhação e mal-estar" (como em Luis Eduardo Soares, criticado por Souza):

Uma teoria social nova necessita construir conceitualmente uma teoria da ação social que permita explicar porque as pessoas, e muito especialmente uma determinada classe de pessoas sentem humilhação e mal-estar social como sua experiência cotidiana (Souza, 2006: 11).

A teoria social alternativa proposta por Souza visa enfrentar a teoria emocional da ação, surgida com Gilberto Freire e desenvolvida por Sérgio Buarque, que explica a cultura do privilégio e a desigualdade brasileira "a partir do acesso diferencial a certo capital social de relações pessoais" (Ibid.: 13). Essa teoria emocional vê o brasileiro como um homem cordial, em que predomina o sentimento sobre o cálculo racional, "criando um mundo dividido entre amigos e inimigos" (loc. cit.). Essa teoria da ação faz parte do imaginário social dominante e teria sido criada para se contrapor a uma teoria instrumental da ação, que predominaria no mundo no norte. Essa teoria emocional fornece, em termos culturais, uma identidade positiva ao brasileiro, e é difícil de ser contraposta, embutindo uma "compensação fantasiosa":

A partir dela, os indivíduos dessas sociedades, percebidas como pré-modernas precisamente pela ênfase na emoção e no sentimento em oposição ao cálculo racional, podem se perceber como mais "calorosos", mais "humanos", mais "hospitaleiros", e até mais "sensuais" do que os indivíduos das frias e insensíveis sociedades avançadas. Foi por conta dessa "satisfação substitutiva" que essa "fantasia compensatória" passou a ser a base da solidariedade interna de sociedades como a brasileira (Souza, 2006: 14).

O imaginário dessa integração emocional cria uma identidade nacional para o brasileiro cordial sob a perspectiva de um mito. A diferença entre brasileiros resulta nesse imaginário concentrada em termos de renda e estilos de vida (homóloga à divisão instaurada pelo laço social condiminial): "por conta disso o progresso econômico entre nós ainda é percebido como uma panaceia para resolver problemas como desigualdade, marginalização e subcidadania" (Souza, 2006: 14).

Ao pensarmos uma teoria da comunicação materialista que seja crítica e sob a perspectiva da epistemologia do sul, como a traz Santos (2010), é preciso, portanto, partir da ideia do antagonismo e da teoria da linguagem que considere o parasita, o ato falho. Além disso, a teoria do reconhecimento de 
Honneth deverá sofrer uma transformação, pois será submetida a uma crítica à antropologia humanista a partir da psicanálise (Dunker, 2015).

A teoria crítica da comunicação do sul (que não é o sul geográfico, mas o pós-colonial) deve pensar a questão da comunicação a partir das buscas concretas de pessoas em sofrimento rumo ao reconhecimento e repensar o laço social de modo diverso do condominial. Isso não deve ser pensado a partir do humanismo, pois não se trata de pensar as demandas de reconhecimento somente como guiadas pela "pressão de universalização de direitos positivos que determinam a universalidade da pessoa jurídica” (Safatle, 2012: 11). Como vimos, as sociedades contemporâneas "são impulsionadas por exigências de reconhecimento de experiências produtivas de indeterminação e negatividade" (loc. cit.). A ideia de Safatle é que não se trata de pensar em instituições que consolidem estruturas disciplinares "que visem produzir indivíduos fortemente do ponto de vista identitário" (loc. cit.), nem de produzir indivíduos de identidades flexíveis "capazes de estabilizar situações de anomia social, identidades fascinadas pela lógica perversa do jogo infinito ruim entre afirmação e transgressão da lei" (Ibid.: 12). Parte-se do desidêntico, para criticar as normas em vigor, de caráter identitário, ligadas à promoção do Eu. "No entanto, em vez de simplesmente pôr uma nova norma, mais inclusiva, ela é abertura àquilo que não se oferece sob a figura da norma, mas do acontecimento" (loc. cit.). Em termos de Dunker (2015), trata-se de recorrer ao pensamento ameríndio para confrontar a razão ocidental (do norte), incorporando, para além de Honneth, as experiências de indeterminação - o encontro contingente na mata, de que nos fala Viveiros de Castro -, trazendo Hegel para um estágio sanduíche na Amazônia, em que lerá um Lacan brasileiro.

Aí entra também a teoria do acontecimento (Prado, 2013b), para nos dar pistas de como pensar a mudança como descontinuidade estésica e política. É por tal razão que Marcondes Filho (2010) busca fazer a sua teoria da comunicação a contrapelo, contra a comunicação que vige no capitalismo globalizado, pensando-a como acontecimental, via Deleuze. Essa comunicação a ultrapassar é um modo de produzir colonialidade e intersubjetividade que formalizaram modos de produzir conhecimento que deu conta das necessidades do capitalismo. Pensar a teoria da comunicação como crítica que emerge no concreto do acontecimento implica em imaginá-la como ruptura, como erupção, como saída do mundo da gestão condominial ou sistêmica, do mundo da promoção do autoempreendedorismo de um eu que busca o sucesso, como experiência desmesurada em termos de intensidade cujas energias brotam das experiências produtivas de indeterminação: "tal experiência produtiva só pode ser corretamente pensada quando somos capazes de abandonar 
a ilusão de que a linguagem pré-filosófica do senso comum já não traz no seu bojo uma figura antropológica do homem à qual deveríamos nos conformar" (Safatle, 2012:313). Trata-se, portanto, como vimos, de criticar a redução egológica do sujeito, ou seja, a "impossibilidade de pensar aquilo que, no interior da experiência, não se submete à forma do Eu" (Ibid.: 315).

Pensar a comunicação a partir do acontecimento é considerar que a "potência de indeterminação que parece habitar todo sujeito é a primeira manifestação de uma experiência de infinitude" (Ibid.). Para Badiou, o acontecimento é o corte num devir de um objeto do mundo por sua autoaparição e "suplementação do aparecer pelo surgimento de uma pegada: o antigo existente tornado existência intensa" (Badiou, 2008: 46). No acontecimento se dá a erupção de um "evanescente separador", ou seja, "um instante intemporal que disjunta o estado anterior de um objeto de seu estado consecutivo" (loc. cit.). $\mathrm{O}$ acontecimento rompe a ordem de um estado de coisas na política, na ciência, na arte ou no amor, e extrai "de um tempo a possibilidade de outro tempo" (Ibid.: 427). Um dos efeitos do acontecimento é o surgimento de um corpo ativo e adequado ao novo presente surgido: "não são as ações e paixões dos múltiplos as que [...] são sintetizadas no acontecimento. É a impressão do acontecimento que magnetiza as multiplicidades e as constitui em corpo subjetivável" (loc. cit.). O acontecimento tem uma grande intensidade no sensível dos corpos. Se houver sujeitos que deem continuidade ao processo de verdade inaugurado pela intensidade do acontecimento, diremos que são sujeitos fiéis ao acontecimento. $\mathbf{M}$

\section{REFERÊNCIAS}

AUSTIN, J. L. How to do things with words. Oxford: Oxford University Press, 1962.

BADIOU, A. Lógicas de los mundos. Buenos Aires: Manantial, 2008.

DERRIDA, J. Limited Inc. Campinas: Papirus, 1991.

DUNKER, C. Mal-estar, sofrimento e sintoma. São Paulo: Boitempo, 2015.

FREIRE FILHO, J. Ser feliz hoje. Rio de Janeiro: Globo Universidade/FGV, 2010.

HABERMAS, J. Teoria do agir comunicativo. São Paulo: Martins Fontes, 2012. HONNETH, A. Luta por reconhecimento. São Paulo: Editora 34, 2003. . La sociedade del desprecio. Madrid: Trotta, 2011.

LANDOWSKI, E. Interações arriscadas. São Paulo: Estação das Letras, 2014. MARCONDES FILHO, C. O princípio da razão durante, tomo v. São Paulo: Paulus, 2010. 
PINHEIRO, A. América Latina: barroco, cidade, jornal. São Paulo: Intermeios, 2013.

PRADO, J. L. A. Convocações biopolíticas dos dispositivos comunicacionais. São Paulo: Educ/Fapesp, 2013a.

Política do acontecimento. Revista Famecos, Porto Alegre, PUC-RS, v. 20, n. 2, p. 495-520, maio-ago. 2013b. Habermas com Lacan. São Paulo: Educ, 2014.

RANCIÈRE, J. O desentendimento. São Paulo: Editora 34, 1996.

SAFATLE, V. Grande hotel abismo. Por uma reconstrução da teoria do reconhecimento. São Paulo: Martins Fontes, 2012.

SANTOS, B. S. Epistemologia do Sul. São Paulo: Cortez, 2007.

SEARLE, J. Speech acts. Nova York: Cambridge University Press, 1970.

SOUZA, J. A invisibilidade da desigualdade brasileira. Belo Horizonte: UFMG, 2006.

ŽIŽEK, S. Absolute recoil: towards a new foundation of dialectical materialism (Kindle edition). Londres: Verso, 2014. . Menos que nada. São Paulo: Boitempo, 2013.

Artigo recebido em 11 de julho de 2015 e aprovado em 13 de outubro de 2015 . 